The Large-Scale

Structure of the

Universe 


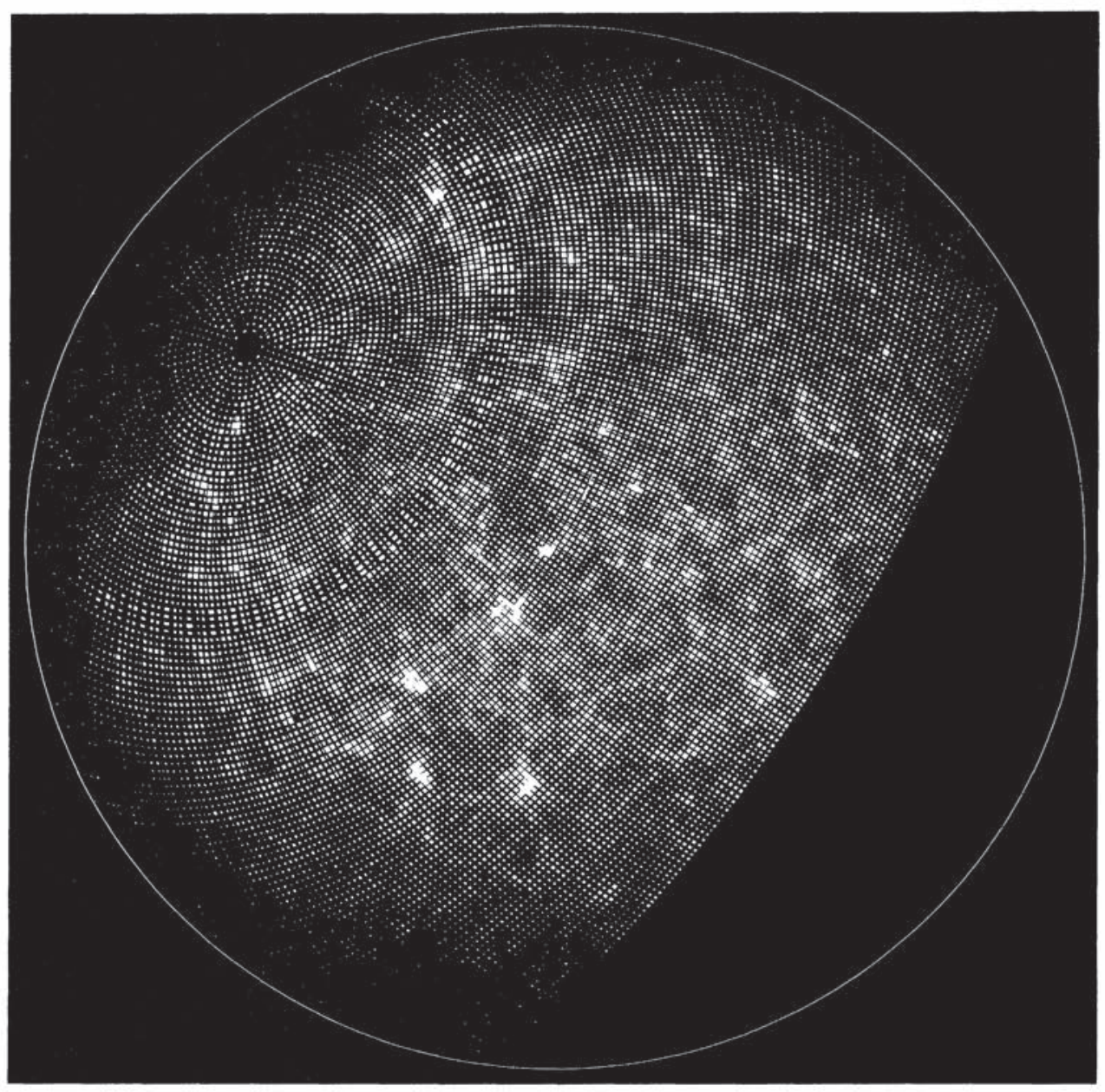

FRONTISPIECE: The large-scale pattern of the galaxy distribution. Each white square represents a sky cell about one degree by one degree in the Lick sample. The size of the white square is proportional to the number of galaxies brighter than 19th magnitude in the cell. The cells are arranged along lines of fixed right ascension and declination. The north pole of the galaxy is at the center of the map and the equator along the edge. (Map by J. A. Peebles and P.J.E. Peebles.) 


\title{
The Large-Scale Structure of the Universe
}

\author{
by \\ P. J. E. Peebles
}

Princeton Series in Physics

Princeton University Press

Princeton, New Jersey 


\section{Copyright (C) 1980 by Princeton University Press, \\ 41 William Street, Princeton, NJ 08540 \\ In the United Kingdom: \\ 6 Oxford Street, Woodstock, Oxfordshire OX20 1TR}

Cover image: Dark matter distribution in the universe, based on the Millennium Simulation, a very large cosmological N-body simulation (more than 10 billion particles).

Courtesy of V. Springel, Max Planck Institute for Astrophysics, Germany

\section{All Rights Reserved \\ press.princeton.edu}

First printed 1980

New paperback printing, 2020

Paperback ISBN 9780691209838

This book was originally published in the Princeton Series in Physics.

For more information on the series, please visit

https://press.princeton.edu/series/princeton-series-in-physics

The Library of Congress has cataloged the cloth edition as follows:

Peebles, Phillip James Edwin.

The large-scale structure of the universe.

(Princeton series in physics)

Bibliography: $\mathrm{p}$.

Includes index.

1. Galaxies. 2. Cosmology. I. Title.

QB857.P43 523.1'12 79-84008

ISBN 0-691-08239-1

ISBN 0-691-08240-5 (pbk.)

Printed in the United States of America 
To Alison 
